\title{
Cultivo protegido de hortalizas en Costa Rica
}

\author{
Carlos Ramírez Vargas' \\ James Nienhuis ${ }^{2}$
}

Fecha de recepción: 14 de febrero del 2011

Fecha de aceptación: 7 de setiembre del 2011

Ramírez, C; Nienhuis, J. Cultivo protegido de hortalizas en Costa Rica. Tecnología en Marcha. Vol. 25, No 2. Abril-Junio 2012. Pág 10-20.

I Ingeniero agrónomo. Escuela de Agronomía, Tecnológico de Costa Rica, sede San Carlos. Teléfono: 2401-3049. Correo electrónico: caramirez@itcr.ac.cr

2 Professor, Departamento de Horticultura, Universidad de Wisconsin. Correo electrónico: nienhuis@wisc.edu 


\section{Resumen}

La horticultura en Costa Rica se ha desarrollado principalmente a campo abierto y se ha concentrado en elValle Central donde predominan las actividades de expansión urbanística y comercial. Muchos de los problemas asociados a la producción hortícola se centran en la alta presencia de plagas y enfermedades que obligan al productor a utilizar plaguicidas químicos con consecuencias nocivas para el ambiente: la horticultura a campo abierto se vuelve muy contaminante e insostenible.

Una alternativa productiva pueden ser los sistemas de cultivos protegidos, en los que se usan estructuras, materiales y equipo; posibilitan la producción de hortalizas en climas adversos y facilitan el control de plagas y enfermedades. Estos sistemas se han usado ampliamente a nivel mundial con gran éxito, pero a nivel del trópico es necesaria la investigación en este campo con el objetivo de implementar o modificar el sistema para que favorezca la producción sostenible de hortalizas.

\section{Palabras clave}

Cultivo protegido,horticultura, plagas y enfermedades, campo abierto, invernadero.

\section{Abstract}

Horticulture in Costa Rica has been development mainly in open field system on the central valley, where the main activities are housing and marketing. Many of the problems associated to horticulture are pests and diseases; for this reason, the farmers use chemical pesticides with negative consequences for the environment. Open field horticulture turns polluting and unsustainable.

Protected culture systems can become an option to produce; these systems use materials and equipment for the production of vegetables in difficult environments and to ease pest and disease control. These systems have been widely used successfully around the world. In the tropic, however, it is necessary to modify the system through research for the production of vegetables sustainably.

\section{Key words}

Protected culture, horticulture, pest and diseases, open field, greenhouse. 


\section{Introducción}

Por mucho tiempo en Costa Rica, la producción de hortalizas se ha llevado a cabo a campo abierto y no en sistemas de cultivo protegido, esto se debe, entre otras razones, a las ventajas de un clima que permite sembrar a lo largo de todo el año, suelos fértiles con aptitud agrícola y una cultura hortícola desarrollada a nivel local. Sin embargo, el cambio climático global, la presión de plagas y enfermedades, el crecimiento urbanístico y comercial han afectado también la actividad hortícola a campo abierto en las zonas tradicionales de cultivo.

Los sistemas de producción de hortalizas en Costa Rica han sido de tipo intensivo, en ellos se consume mucha mano de obra y se utilizan grandes cantidades de agroquímicos (La Nación, 2005). La topografía de los terrenos casi no permite el uso de maquinaria agrícola para preparación de suelos ni para cosecha, ha predominado la finca de tamaño pequeño que puede oscilar en un área promedio de I a 5 hectáreas y el horticultor ha desarrollado su actividad con el apoyo de mano de obra familiar. Como las fincas o predios son pequeños, es común encontrar en una comunidad hortícola a grupos asociados de productores uniendo esfuerzos para mejorar su capacidad comercial, y así facilitar el mercadeo de sus productos (Murillo, 2008).

Algunas hortalizas se han sembrado en sistemas de asocio de cultivos, como es el caso del tomate (Lycopersicum esculentum) y del chile dulce (Capsicum annum), que se cultivan asociados al cultivo de café (Coffea arabica). En las fincas es común encontrar plantaciones de tomate y chile dulce en lotes con plantas de café recién sembradas o podadas, que permiten el establecimiento temporal de un cultivo de ciclo anual como son estas solanáceas (Tomatico S.A., 2008). También la rotación de cultivos ha sido una práctica común en el cultivo de hortalizas de ciclo corto, se alternan en un mismo lote siembras de hortalizas de familias diferentes; por ejemplo, papa (Solanum tuberosum) y col (Brassica oleraceae).

En Costa Rica, las principales áreas de cultivo de hortalizas se han concentrado en el Valle Central, ubicado en el centro del territorio, y a una altitud que oscila desde los 700 a los 2000 metros sobre el nivel del mar. Los tipos de suelo predominantes son de origen volcánico de textura franco a franco limosa (Bertsch, 2006). Las principales ciudades del país están ubicadas allí donde el crecimiento

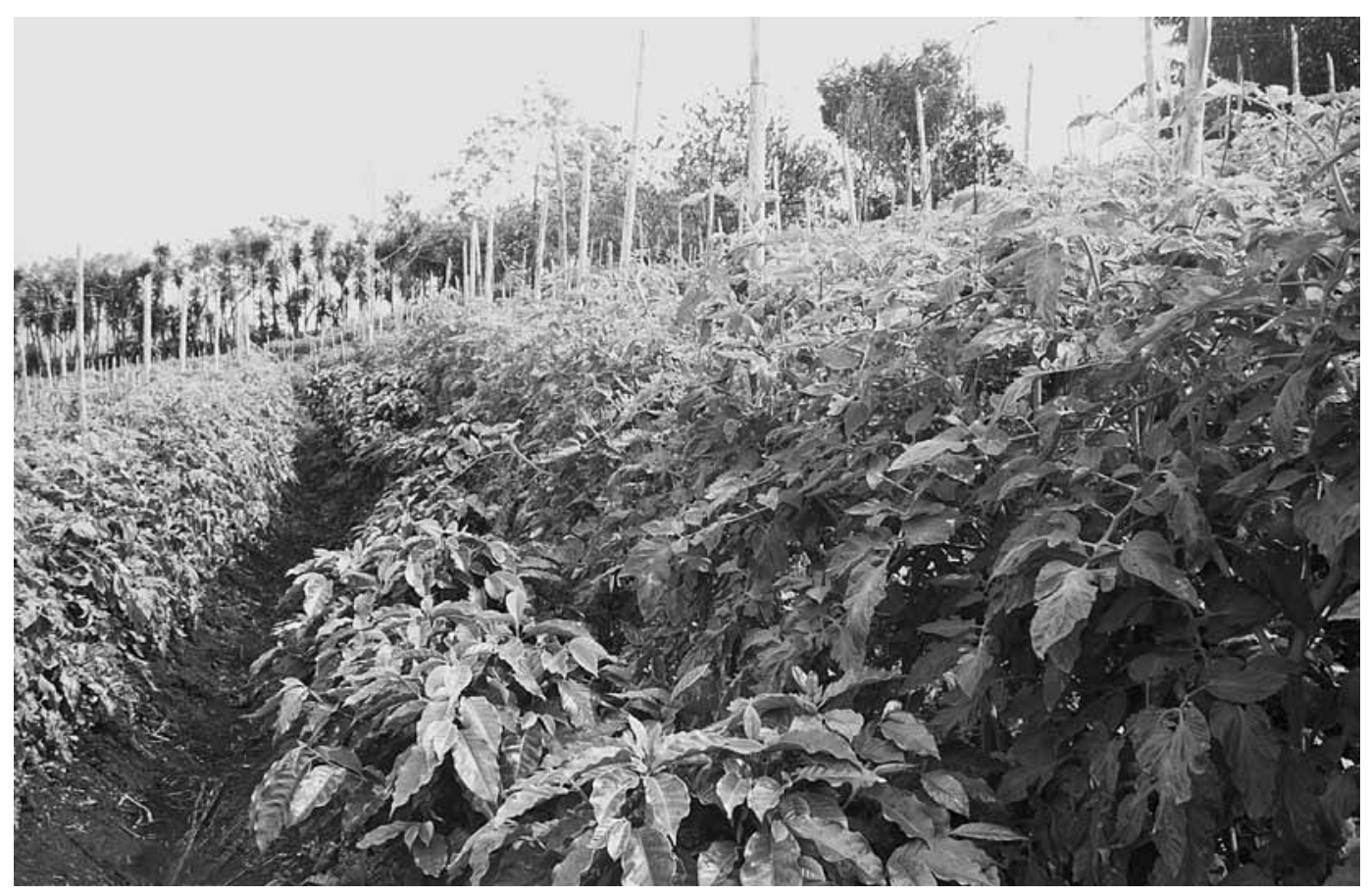

Figura I. Cultivo de tomate a campo abierto asociado a plantaciones de Café en la provincia de Alajuela, Costa Rica (Foto: Carlos Ramírez Vargas). 
urbanístico y comercial es cada vez mayor (Informe del Estado de la Nación, 2003).

Las zonas tradicionales de cultivos hortícolas en Costa Rica se han cambiado por otras actividades, como lo son la construcción de residenciales y el desarrollo comercial e industrial, desplazando la agricultura a terrenos en zonas marginales o con aptitudes de suelo y clima inconvenientes para los cultivos hortícolas, esta situación es típica del cambio en el uso del suelo en países sin planificación territorial (Vásquez, 1993, citado por Bertsch, 2006), como consecuencia los terrenos se vuelven más escasos e injustificables desde el punto de vista económico para la actividad hortícola tradicional.
La agricultura a campo abierto puede ser muy contaminante, sobre todo cuando es afectada por condiciones climáticas adversas como fuertes lluvias, que incrementan la erosión de suelo a nivel superficial y por consiguiente de los fertilizantes y pesticidas aplicados. Las condiciones climáticas adversas provocan en la horticultura problemas de tipo fitosanitario que obliga al agricultor a usar pesticidas químicos en exceso; la horticultura a campo abierto en el trópico se vuelve arriesgada.

\section{Condición agroecológica de Costa Rica}

Costa Rica es un país situado en el istmo de América Central, con una topografía montañosa. Las cadenas de montañas o cordilleras atraviesan el

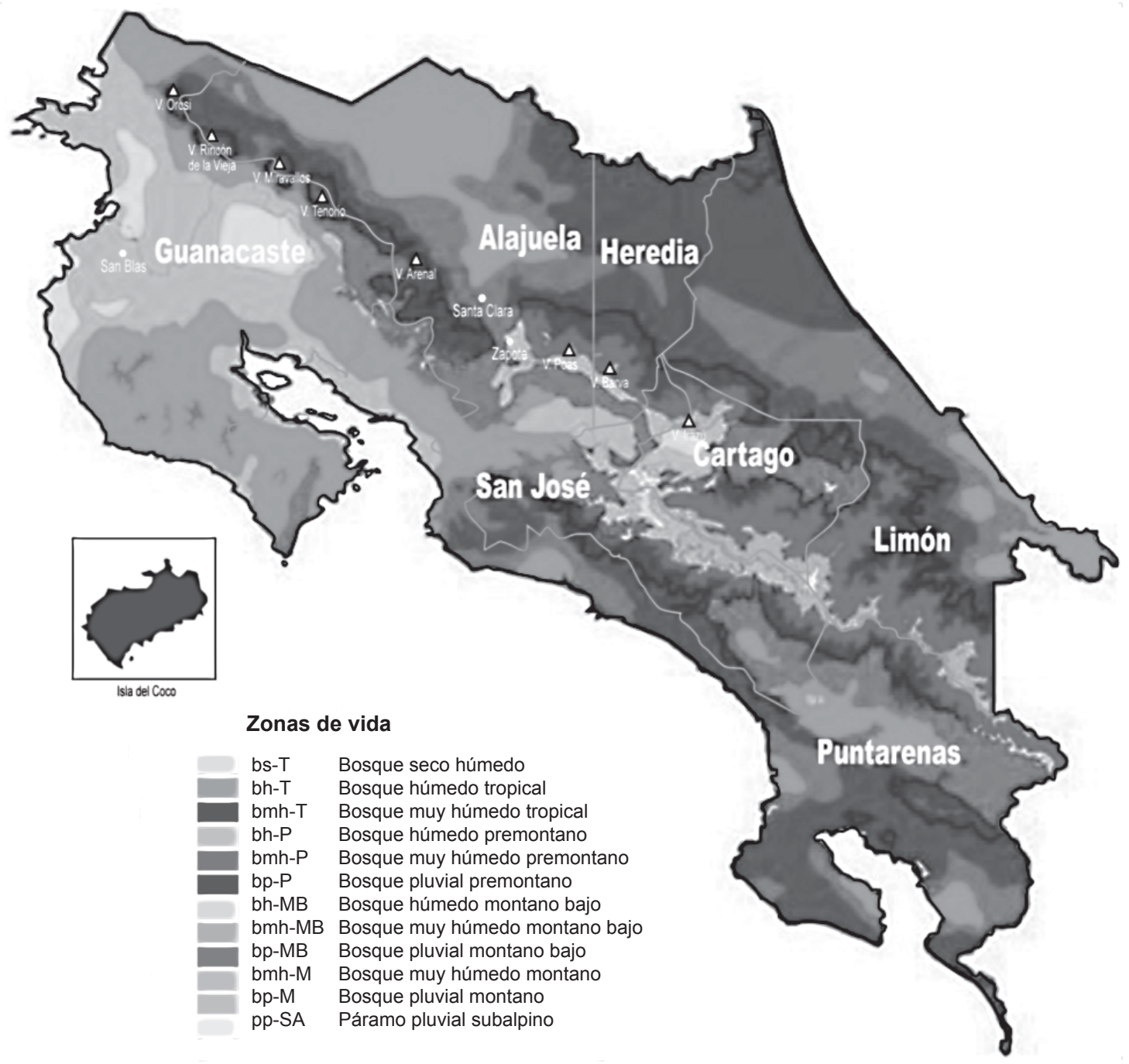

Figura 2. Mapa de Costa Rica con zonas de vida según Holdbridge (Fuente: Inbio, 2005 citado por SIREFOR, 2007). 
centro del país a todo lo largo, y esto produce una serie de condiciones ambientales muy diversas por influencia de las corrientes de aire que provienen del mar Caribe y del Océano Pacífico. La topografía montañosa genera también una serie de microclimas con altitudes que oscilan desde el nivel del mar hasta los 4000 msnm.

Estos microclimas permiten el desarrollo de muchas actividades agrícolas con muchos cultivos diferentes adaptados a las condiciones climáticas imperantes en cada zona; por ejemplo, el café se cultiva en altitudes superiores a los 1000 msnm y predominantemente en el Valle Central; por otra parte, en zonas de altitudes bajas predominan los cultivos de tipo más extensivo como los granos básicos, la caña de azúcar, palma aceitera, y algunos de exportación como la piña y el melón, entre muchos otros.

\section{Problemática de la producción} de hortalizas en Costa Rica

La mayoría de las siembras de cultivos hortícolas en Costa Rica no son estacionales, la presencia de plagas y enfermedades durante todo el año ocurre como consecuencia del constante cultivo que favorece la permanencia de inóculo en el campo, dentro de estas plagas tenemos insectos, ácaros, hongos, bacterias y virus. Las condiciones ambientales también las han favorecido, ya que se presentan altas temperaturas y precipitaciones, que favorecen el desarrollo de epifitas.

Cuadro I. Algunas plagas reportadas en cultivos hortícolas de Costa Rica (Ministerio de Agricultura de Costa Rica, 2004).

\begin{tabular}{|c|c|c|}
\hline Nombre de la plaga & Grupo taxonómico & Cultivos hospederos \\
\hline Phyllophaga spp & Col:Scarabaeidae & Hortalizas en general \\
\hline \multirow[t]{3}{*}{ Myzus persicae } & Hom:Aphididae & Lycopersicum esculentum \\
\hline & & Capsicum spp. \\
\hline & & Cucumis melo \\
\hline Atta sp. & Hym:Formicidae & Hortalizas en general \\
\hline \multirow[t]{3}{*}{ Heliothis virescens } & Lep:Noctuidae & Lycopersicum esculentum \\
\hline & & Capsicum spp. \\
\hline & & Cucumis melo \\
\hline \multirow[t]{3}{*}{ Spodoptera spp. } & Lep:Noctuidae & Lycopersicum esculentum \\
\hline & & Capsicum spp. \\
\hline & & Cucumis melo \\
\hline \multirow[t]{2}{*}{ Trichoplusia ni } & Lep:Noctuidae & Lycopersicum esculentum \\
\hline & & Capsicum spp. \\
\hline Manduca sexta & Lep:Sphingidae & Lycopersicum esculentum \\
\hline \multirow[t]{2}{*}{ Polyphagotarsonemus latus } & Acari:Tarsonemidae & Lycopersicum esculentum \\
\hline & & Capsicum spp. \\
\hline \multirow[t]{3}{*}{ Tetranychus urticae } & Acari:Tetranychidae & Lycopersicum esculentum \\
\hline & & Capsicum spp. \\
\hline & & Cucumis melo \\
\hline Diabrotica spp. & Col:Chrysomelidae & Hortalizas en general \\
\hline Epitrix cucumeris & Col:Chrysomelidae & Hortalizas en general \\
\hline Liriomyza sativae & Dip:Agromyzidae & Hortalizas en general \\
\hline \multirow[t]{3}{*}{ Bemisia tabaci } & Hom:Aleyrodidae & Lycopersicum esculentum \\
\hline & & Capsicum spp. \\
\hline & & Cucumis melo \\
\hline \multirow[t]{3}{*}{ Trialeurodes sp. } & Hom:Aleyrodidae & Lycopersicum esculentum \\
\hline & & Capsicum spp. \\
\hline & & Cucumis melo \\
\hline Keiferia lycopersicella & Lep:Gelechiidae & Lycopersicum esculentum \\
\hline Agrotis spp & Lep:Noctuidae & Hortalizas en general \\
\hline Anthonomus eugenii & Col: Curculionidae & Capsicum spp. \\
\hline
\end{tabular}


Cuadro 2. Algunas enfermedades reportadas en cultivos hortícolas de Costa Rica (Ministerio de Agricultura de Costa Rica, 2004)

\begin{tabular}{|l|l|}
\hline \multicolumn{1}{|c|}{ Nombre de la enfermedad } & \multicolumn{1}{c|}{ Agente causal } \\
\hline Marchitez bacteriana & Ralstonia solanacearum \\
Tizón tardío & Phythophtora infestans \\
Tizón temprano & Alternaria solani \\
Marchitez fungosa & Fusarium oxysporum \\
Marchitez fungosa & Sclerotium rolfsii \\
Peca bacteriana & Pseudomonas syringae \\
Mancha bacteriana & Xanthomonas vesicatoria \\
Mildiu velloso & Pseudoperonospora cubensis \\
Mildiu polvoso & Liveillula taurica \\
Esclerosis & Sclerotinia sclerotium \\
Mal del talluelo & Pythium sp. \\
& Rhizoctonia solani \\
Pudrición bacteriana & Erwinia carotovora \\
Cercospora & Cercospora capsici \\
\hline
\end{tabular}

La presencia del cultivo a lo largo de todo el año y las condiciones ambientales favorables provocan que la presión de plagas y enfermedades vaya en aumento; por esta razón, el horticultor se ve obligado a hacer aplicaciones de pesticidas químicos para tratar de recuperar su inversión; sin embargo, las constantes aplicaciones provocan serios problemas ambientales, ya que en la horticultura a campo abierto la degradación del suelo es alta y la contaminación por exceso de aplicación se suma a este problema (Estado de la Nación, 2003).

El uso indiscriminado de pesticidas ha provocado una alta presión de selección sobre las plagas, y hay carencia de materiales genéticos resistentes a las principales plagas y enfermedades (Tomatico S.A., 2008), en Costa Rica según informes de la Cámara de Importadores de Insumos Agropecuarios de Costa Rica, se importaron en el 2006 un equivalente a $14 \mathrm{~kg}$ de pesticidas sintéticos per cápita. Debido al constante incremento en el costo de los pesticidas, el horticultor aplica los más baratos del mercado, siendo estos en su mayoría productos no autorizados para sus cultivos o bien son de alta toxicidad y residualidad. El agricultor desconoce muchas veces como se dosifican y para qué se usan, por lo que es cuestionable el uso que hace de ellos (La Nación, 2005). La venta de agroquímicos en Costa Rica es libre por lo que cualquier persona puede tener acceso a los productos autorizados para la venta (Coto, 2003).

En los cuadros I y 2 se presentan unas listas de plagas y enfermedades para algunos cultivos hortícolas de Costa Rica. Como se puede apreciar la lista es larga y la diversidad de individuos es alta, muchos de estos insectos crean problemas dobles al ser vectores de virus y otras enfermedades, como es el caso de Myzus persicae y Bemisia tabaci; muchas de estas plagas y enfermedades son específicas para algunos cultivos y otros tienen una amplia gama de hospederos. Su control se ha llevado a cabo tradicionalmente utilizando plaguicidas químicos, y en algunos casos se ha empezado a utilizar control biológico con hongos antagonistas. En localidades de cultivo intensivo y extensivo de algunos cultivos como melón y chile dulce, se han provocado infestaciones altas de estas plagas y se han salido de control, hasta tener que declarar la zona en cuarentena por alta incidencia de plagas (Departamento fitosanitario del estado costarricense, 2007).

\section{Horticultura protegida como opción productiva}

La horticultura protegida es una alternativa productiva para los horticultores de Costa Rica. El uso de invernaderos u otros sistemas de protección 
de plantas ha sido ampliamente usado alrededor del mundo con gran suceso (Wittwer y Castilla, 1995).

Frente a condiciones climáticas adversas, es posible sembrar dentro de estructuras diseñadas especialmente para poder modificar o controlar el clima circundante a las plantas de cultivo. El cultivo protegido supone la creación de un ambiente que proteja a las plantas y permita controlar al máximo factores de producción como : el uso del agua, la fertilización, la luz, $\mathrm{CO}_{2}$, temperatura y humedad (Castilla, 2005; Gil-Vázquez et al, 2003). La estructura básica para el cultivo protegido, llamada invernadero, permite el cultivo de hortalizas minimizando el efecto de las plagas y enfermedades en localidades con condiciones climáticas adversas. El cultivo protegido de hortalizas en el trópico nos permite disminuir sustancialmente las aplicaciones de plaguicidas químicos y puede potenciarse el uso del control biológico al tener un ambiente más controlado (Obregón, 2008, comunicación personal).

Los invernaderos son estructuras que deben ser diseñadas de acuerdo con las condiciones ambientales del lugar o localidad donde se van a establecer, así como considerar el cultivo por sembrar, por tal razón, es de suma importancia que el diseño se adapte bien a las condiciones ambientales prevalecientes de la zona. Los diseños de invernaderos de clima templado pueden no funcionar en condiciones tropicales, por tanto se hace necesario diseñar e investigar el comportamiento funcional de diferentes tipos de invernaderos dentro del ambiente tropical.

Debido a que en Costa Rica existen diversos tipos de microclimas generados por su condición topográfica (figura 2), los tipos de invernaderos deberán diseñarse y construirse tomando en cuenta el clima local. Es muy importante considerar algunos

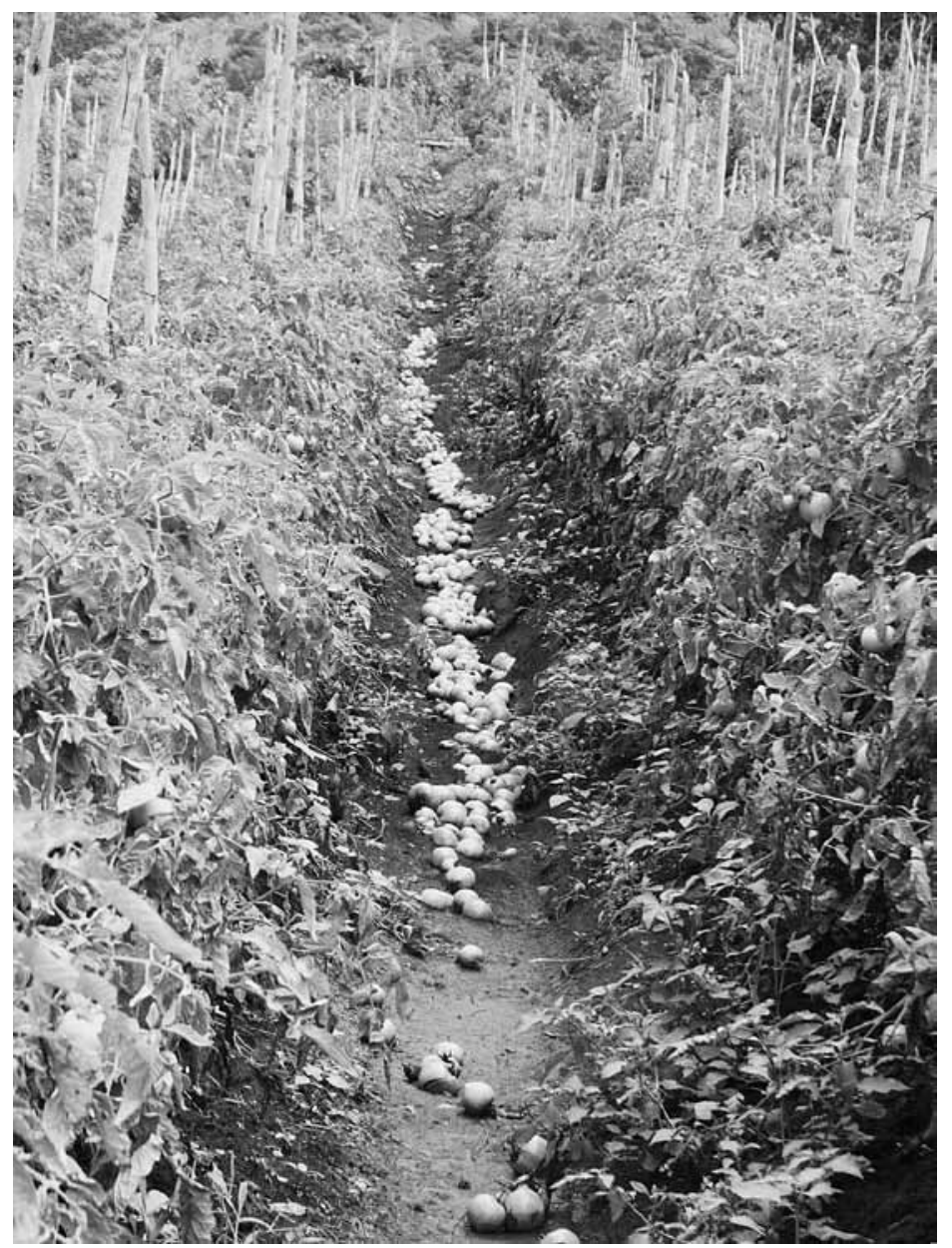

Figura 3. Daño causado por fuertes lluvias a una plantación de tomate a campo abierto en Alajuela (Valle Central), Costa Rica (Foto: Carlos Ramírez Vargas). 


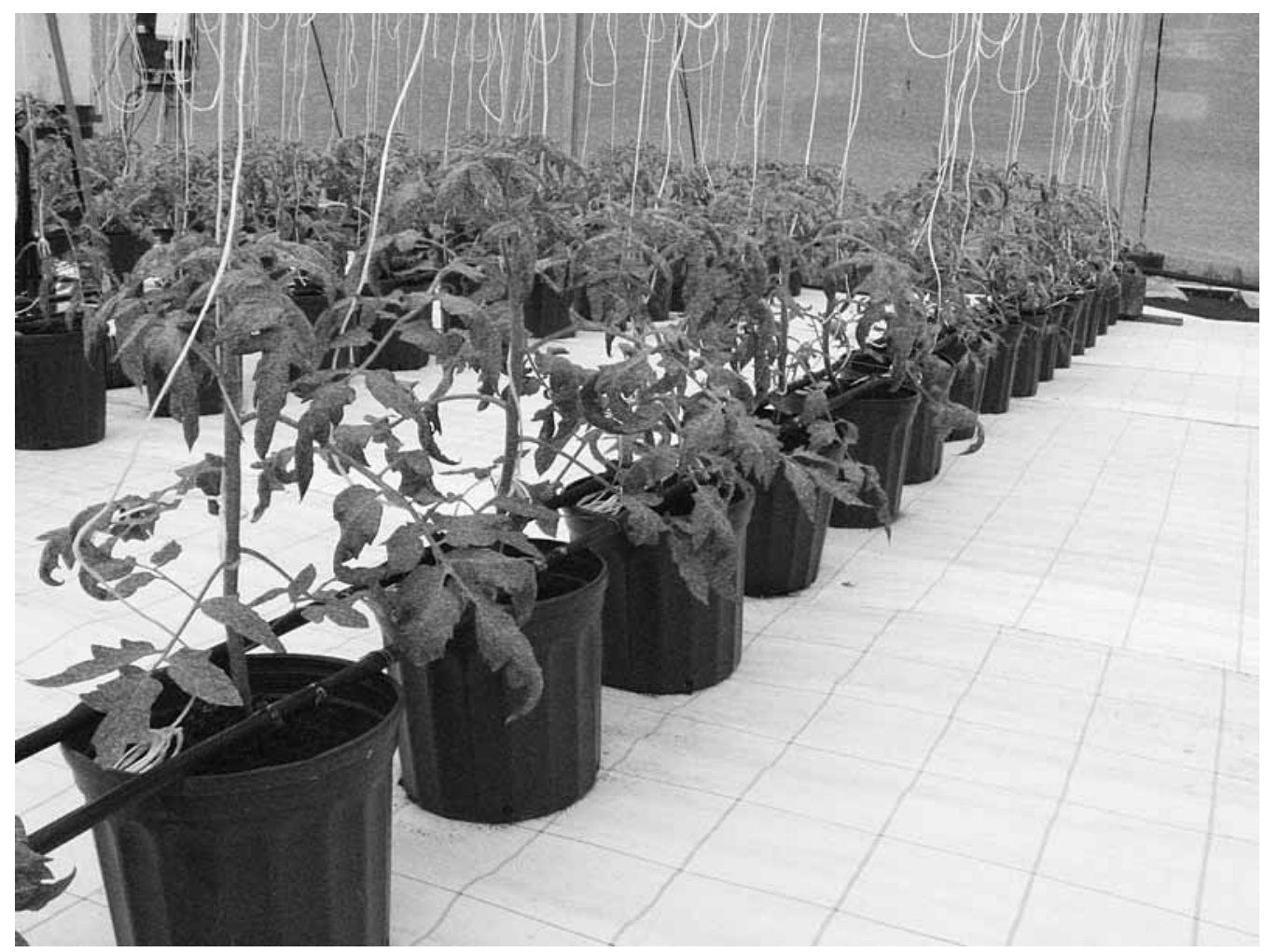

Figura 4. Cultivo de tomate en un invernadero de la sede San Carlos del Tecnológico de Costa Rica (zona norte de Costa Rica), utilizando contenedores individuales con sustrato y piso blanco para mejorar la reflectancia de la luz (Foto: Carlos Ramírez Vargas).

principios del diseño agronómico de un invernadero, y uno fundamental es la ventilación; esta se debe promover en la medida de lo posible mediante el mismo diseño del invernadero y puede ser ayudado con accesorios o equipamiento para ventilación; otro aspecto relevante es que el invernadero en el trópico debe ofrecer una adecuada protección contra la lluvia.

En Costa Rica se vislumbran regiones potenciales para la producción de hortalizas en ambientes protegidos, una de ellas está ubicada en el noroeste del valle Central y corresponde a la comunidad de Zarcero, debido a que es una localidad cuya población tiene una tradición hortícola muy fuerte y han sido precursores de sistemas alternativos de producción de hortalizas en el país, como la horticultura orgánica. Zarcero se ubica a una altitud que oscila entre los 1500 y los 1800 msnsm, con un régimen de lluvias moderado pero con dos estaciones definidas, una seca y otra lluviosa.

Otras regiones con potencial son la Zona Norte y el Pacífico Norte; la primera caracterizada por las altas precipitaciones y temperaturas durante todo el año, con luminosidad variable; y la segunda, por tener dos estaciones bien definidas, una de noviembre a mayo de condiciones secas de alta temperatura, luminosidad y viento, y otra estación lluviosa y de altas temperaturas. Estas dos últimas regiones no poseen una cultura hortícola desarrollada, como es el caso de la localidad de Zarcero, pero se promueve un cambio en la cultura agrícola debido a la presión por diversificar sus actividades con miras a la seguridad alimentaria.

Aunque las condiciones ambientales sean muy diversas y haya ausencia de cultura hortícola, la tecnología de cultivo protegido ofrece un alto potencial para la horticultura protegida en estas regiones.

Existen muchas razones por las que se justifica el uso de invernaderos en el trópico, desde el punto de vista técnico, los invernaderos permiten controlar mejor las variables de producción de los cultivos, como son el riego, la aplicación de fertilizantes, el manejo de la biomasa del cultivo a través del tutorado, la 


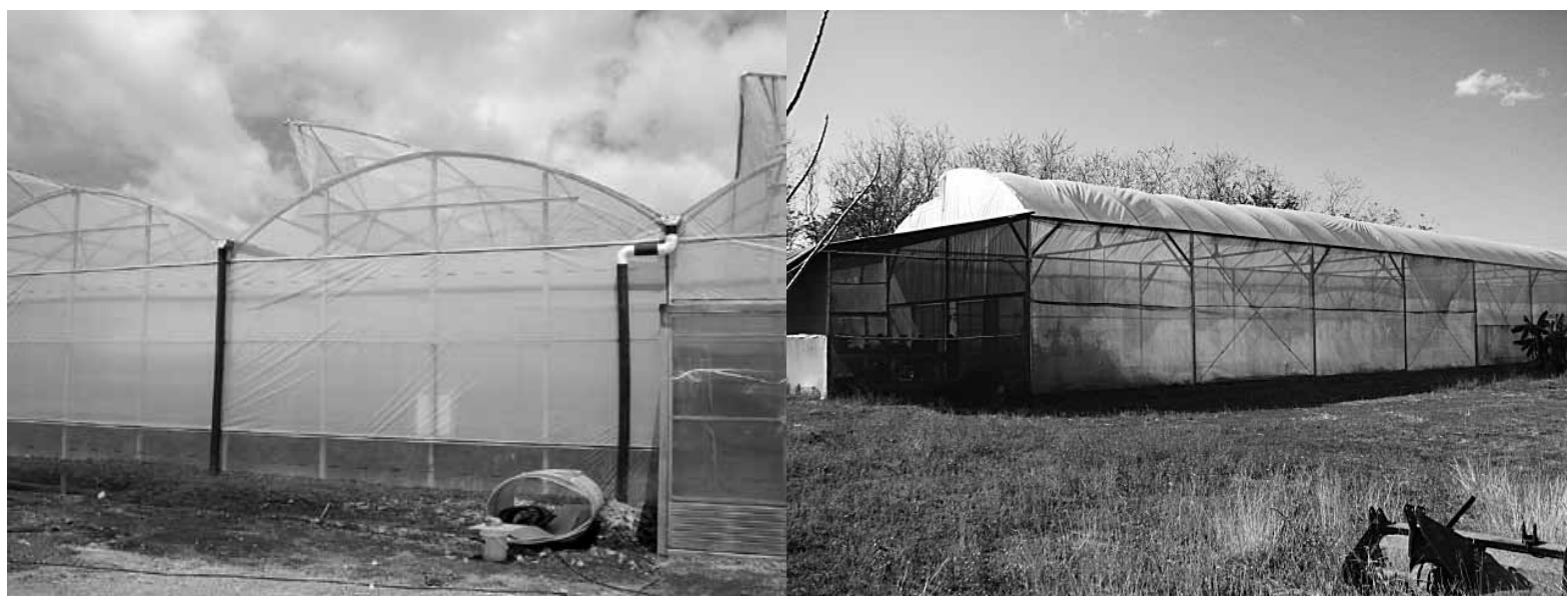

Figura 5. Dos invernaderos en zonas con climas diferentes en Costa Rica, izquierda la localidad de Zarcero, y derecha para el Pacífico Norte (Fotos: Carlos Ramírez Vargas).

poda y el uso de sustratos para cultivo (en caso de no usar el suelo). Con esta tecnología se facilita la implementación de equipo y uso de materiales para modificar el ambiente, como lo son los ventiladores, los muros húmedos, el piso de color blanco para reflectancia de luz entre otros, el invernadero también permite la automatización de algunos procesos por medio de dispositivos electrónicos de control como programadores de riego.

En lugares donde el suelo no presenta condiciones aptas para los cultivos, ya sea por presencia de plagas y enfermedades o por problemas de tipo químico y físico, se puede hacer uso de la tecnología hidropónica abierta o cerrada, usando sustratos en contenedores que permiten sembrar las plantas evitando los problemas del suelo y así poder producir en localidades con suelos marginales o inadecuados.

Desde el punto de vista de sostenibilidad, los sistemas de producción hortícola a campo abierto en Costa Rica tienen muchos inconvenientes. De acuerdo con Altieri (2000) y Poincelot (2004), un aspecto por tomar muy en cuenta para establecer sistemas de producción sostenibles, es la disminución gradual del uso de pesticidas hasta llegar a utilizar controles naturales de plagas. En Costa Rica la presión de plagas y enfermedades es tan alta en cultivos a campo abierto, que obliga al agricultor a hacer uso de los plaguicidas como alternativa unilateral para el control.

Los sistemas de producción en ambientes protegidos o controlados son vistos por algunos como sistemas muy artificiales, pero no se pueden excluir de este tipo de sistemas los elementos naturales asociados al desarrollo de las plantas y su fisiología. La tecnología debe favorecer la sostenibilidad y promover prácticas acordes con la agricultura alternativa. La creación de microclimas favorables a la producción de hortalizas puede ser visto como una práctica favorable a favor de la sostenibilidad (Altieri, 2000 y Poincelot, 2004). Un sistema protegido de producción de hortalizas puede hacer una utilización más eficiente del recurso agua; se puede almacenar agua de lluvia recolectada por las canaletas del invernadero y ser utilizada como agua para riego o fertirriego, y utilizar además sistemas de aplicación del agua de tipo localizado que favorecen la eficiencia de su uso.

Otra ventaja de la producción en sistemas protegidos es que pueden ser parte de un sistema más diverso de producción, ya que al tratarse de un sistema más cerrado y aislado puede estar inmerso dentro de un sistema finca diversificado donde se lleven a cabo otros tipos de producción, e incluso se pueden aprovechar las sinergias existentes con miras a la maximización en el aprovechamiento de recursos internos.

En Costa Rica existen experiencias positivas de producción de hortalizas en invernadero por parte de agricultores y algunos grupos organizados; muchos de ellos han manifestado por medio de entrevistas que la tecnología requiere mucha investigación, pero que ofrece un gran potencial como alternativa sostenible de producción de hortalizas ante el aumento constante de los agroquímicos y los cambios climáticos a nivel global (Murillo, 2008). 
Cuadro 3. Productividad comparativa de diferentes hortalizas cultivadas a campo abierto y en invernadero en Costa Rica según referencia de productores

\begin{tabular}{|c|c|c|c|}
\hline Cultivo & $\begin{array}{c}\text { Producción a campo } \\
\text { abierto }\end{array}$ & $\begin{array}{c}\text { Producción en } \\
\text { invernadero }\end{array}$ & $\begin{array}{l}\text { Referencia de } \\
\text { productores }\end{array}$ \\
\hline Tomate & $5 \mathrm{Kg} / \mathrm{m}^{2}$ & & Tomatico S.A. (2007) \\
\hline Tomate & & $9,6 \mathrm{Kg} / \mathrm{m}^{2}$ & Segura et al (1999) \\
\hline Chile dulce & 20 frutos/planta & & Alfaro, R (2008) \\
\hline Chile dulce & & 50 frutos/planta & $\begin{array}{l}\text { Asoc. Mujeres activas } \\
(2008)\end{array}$ \\
\hline Chile dulce & & 43 frutos/planta & Campos, M (2008) \\
\hline Melón & I,5 Kg/planta & & La Costeña S.A (2007) \\
\hline Melón & & 2,5 Kg/planta & Ramírez, C (2006) \\
\hline Chile jalapeño & I,5 Kg/planta & & $\begin{array}{l}\text { Asoc. Hort.SanBlas } \\
(2007)\end{array}$ \\
\hline Chile jalapeño & & $5 \mathrm{~kg} /$ planta & $\begin{array}{l}\text { Asoc. Hort.San Blas } \\
(2007)\end{array}$ \\
\hline
\end{tabular}

La producción de hortalizas en Costa Rica, mediante el uso de la tecnología del cultivo protegido, puede ser una alternativa sostenible de producción, siempre y cuando se obtengan altas productividades y calidad en el producto final, que permita una comercialización basada en un producto de alta calidad y de bajo uso de pesticidas químicos. Se hace necesario llevar a cabo investigación y validación de sistemas de cultivo protegido en zonas con potencial de producción a futuro, donde este tipo de tecnología permita disminuir los efectos negativos del clima circundante que limitan la productividad de muchas especies de hortalizas a campo abierto.

\section{Agradecimiento}

A las siguientes personas e instituciones, sin las cuales hubiera sido imposible llevar a cabo el experimento que dio origen a esta publicación: Vicerrectoría de Investigación y Extensión del Tecnológico de Costa Rica (VIE), Consejo Nacional de Ciencia y Tecnología (Conicit), Dr. James Nienhuis, del Departamento de Horticultura de la Universidad de WisconsinMadison; a la Asociación de horticultores de San Blas (Guanacaste), y al señor Humberto López, de Zapote de Alfaro Ruiz.

\section{Bibliografía}

Alfaro, R. (2008). Comunicación personal, entrevista sobre producción de chile dulce a campo abierto. San Antonio de Belén, Heredia, Costa Rica.

Altieri, M; Nichols, C. (2000). Agroecología teoría y práctica para una agricultura sustentable. Programa de las naciones Unidas para el Medio Ambiente, Iera. Edición, México.

Asociación de Horticultores de San Blas. (2007). Comunicación personal con la presidenta, doña Marita Jaen Rivera. Carrillo, Guanacaste, Costa Rica.

Asociación de Mujeres activas del Invu de Peñas Blancas. (2008). Comunicación personal con la presidenta, doña Adonay Palma. Peñas Blancas, San Ramón Costa Rica.

Bertsch, F. (2006). El Recurso tierra en Costa Rica. Agronomía Costarricense 30(I), I33- 156.

Cámara de Importadores de Insumos Agropecuarios. (2006). Informe anual de labores. San José, Costa Rica.

Campos, M. (2008). Efecto de la inoculación de sustratos con trichoderma sobre el crecimiento y producción de plantas de chile dulce (capsicum annuum) bajo ambiente protegido. Tesis de licenciatura en Agronomía, Instituto Tecnológico de Costa Rica.

Castilla, N. (2004). Invernaderos de plástico tecnología y manejo. Mundi Prensa, España, 457pp.

Coto, R. (2003). Informe ministerial en salud y agricultura. Organización Panamericana de la Salud. 
Departamento Fitosanitario del Estado. (2007). Comunicación personal de agentes de extensión. Guanacaste, Costa Rica.

Estado de la Nación. (2003). Noveno Informe 2002. San José, Costa Rica.

Gil-Vázquez, l; Sánchez del Castillo, F \& Miranda-Velázquez, I. (2003). Producción de jitomate en hidroponía bajo invernadero. Serie de publicaciones Agribot, Chapingo, México. 90 pp.

Instituto Meteorológico Nacional. (2008). Comunicación personal. San José, Costa Rica.

La Costeña S.A. (2007). Información del gerente agrícola a cargo de la producción de melón, comunicación personal.

Loaiza,V. (20 de febrero del 2005). Ticos comen vegetales con exceso de plaguicidas. La Nación.

Ministerio de Agricultura y Ganadería. (2004). Listado de plagas en cultivos de importancia económica de Costa Rica. San José, Costa Rica. Obtenido desde www.protecnet.go.cr/laboratorios/plagcul/cultivop.htm

Murillo, M. (2008). Entrevista productores de Zarcero, comunicación personal. Zarcero, Costa Rica.
Poincelot, R. (2004). Sustainable Horticulture today and tomorrow. Prentice Hall, Estados Unidos.

Ramírez, C. (2006). Comunicación personal, Heredia, Costa Rica.

Segura, D;Villalobos, M \& Hidalgo, N. (1999). Producción de tomate en invernadero. Congreso agronómico nacional de Costa Rica.

Sirefor. (2007). En:

http://www.google.co.cr/imgres?imgurl=http://www. sirefor.go.cr/imagenes/cr.jPG\&imgrefurl=http://www. sirefor.go.cr/biodiversidad.html\&usg=_8RB4zkzOD6 | 3AlnjeB9hLeOpua8 $=\& h=455 \& \mathrm{w}=485 \& \mathrm{sz}=4 \mathrm{I} \& \mathrm{hl}=\mathrm{es}$ \&start= | \&sig2=yb0LO7emWmlpR55IWkaaTQ\&um $=\mid$ \&itbs $=\mid$ \&tbnid=ofcKGV_KZ_6PM:\&tbnh $=|2| \& t b$ $n w=129 \& p r e v=i m a g e s \% 3 F q \% 3 D m a p a \% 2 B$ costa \%2Brica\%2B\%25C3\%25A I reas\%2Bde\%2Bvida\% 26um\%3DI\%26hl\%3Des\%26sa\%3DG\%26tbs\%3 Disch: I \&ei=uYcCTOmZN4KB8gaa8oyiDQ

Tomatico S.A. (2008). Comunicación personal con el gerente, Milton Castillo. Heredia, Costa Rica.

Wittwer, S.H \& Castilla, N. (1995). Protected cultivation of horticultural crops worldwide. HortTechnology. Vol. 5 ( I ) 6-22. 